
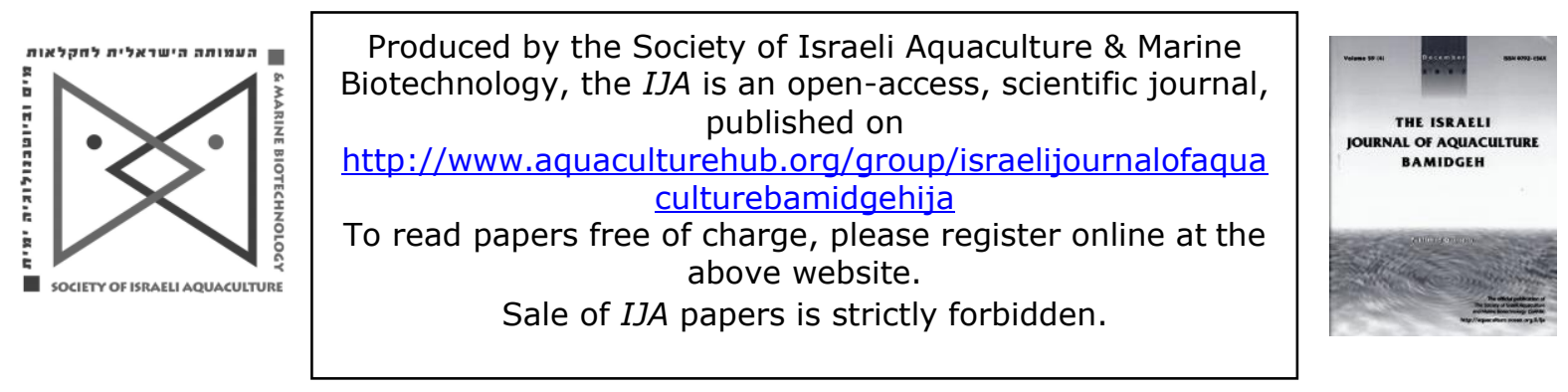

\title{
Effect of Ginseng Root (Araliaceae sp.) Extracts on Sperm Quality Parameters and Reproductive Performance in Rainbow Trout (Oncorhynchus mykiss)
}

\author{
Sonmez A.Y., Ozdemir R.C. ${ }^{*}$, Bilen S., Kadak A.E. \\ Kastamonu University, Faculty of Fisheries and Aquaculture, Department of Basic \\ Sciences, Kastamonu, Turkey
}

Keywords: Ginseng root; rainbow trout; sperm quality

\begin{abstract}
In this study, ginseng root extract was manufactured and used as a food additive for 8 to 9 -month old male rainbow trout (Oncorhynchus mykiss). The extracts were added to the food in two different ratios, $1 \mathrm{~g} / \mathrm{kg}$ and $2 \mathrm{~g} / \mathrm{kg}$. The control group was given a commercial feed with no additive. The fish ate the provided feed for 120 days ad libitum. Sperm samples were taken from fish every 30 days. We observed that the gonadosomatic index (GSI) in the experimental groups was higher than in the control group. Motility duration of groups 1 and 2 was 10 seconds more than the control group. Sperm density averages (SDA) were $7.74 \pm 0.61 \times 10^{9}, 8.62 \pm 0.53 \times 10^{9}$ and $11.27 \pm 0.78 \times 10^{9}$, respectively. All sperm samples taken from each experimental group were used for fertilization. Fertilization ratios of control and experimental groups were $65 \pm 10 \%, 84.9 \pm 5 \%$ and $90 \pm 6 \%$, respectively. The hatching ratio was also very high in the extract added groups compared to the control group.
\end{abstract}

* Corresponding author. Tel.: +90 539553 8658, e-mail: rozdemir@kastamonu.edu.tr 


\section{Introduction}

Medicinal plant extracts have been used since ancient times for different purposes, such as food supplements, cosmetics, and drugs (Bhuvaneswari and Balasundaram, 2006). In recent years, herbal supplements have been tested as an alternative to chemicals in aquaculture. Plant-based additives in aquaculture are used to increase weight gain and feed efficiency in cultured fish (Dada 2015; Bilen et al., 2018).

The growing demand for high quality fish sperm has generated interest in research aimed to enhance fish fertility. The continuing expansion of aquaculture, has created a need to replace the increasing detrimental use of chemicals with natural vegetal sources (Adeparusi et al. 2010). Medicinal plants that were once considered of no value are now being investigated, evaluated, and developed into drugs with little or no side effects (Adedeji et al. 2006b; Bai et al., 2009). The use of medicinal plants as fertility enhancers in aquaculture is now receiving more attention. Extract from Centella asiatica seed to enhance fertility in Clarias gariepinus females was used in the past (Dada and Ajiore, 2009).

Ginseng is a popular herbal product used for healthcare as well for fertility and disease treatments in Asia and is currently distributed to 35 countries around the world (Baeg and So 2013). It is cultivated in Korea, Japan, China, and Russia (Gillis 1997; Attele et al. 1999). There is a considerable body of literature describing the pharmacognosy of ginseng, including effects on the central nervous system, metabolism, growth performance, antioxidant activities, immune function, and cardiovascular system. In dogs, an injection of ginseng alcohol extract was reported to reduce blood pressure without apparent depression of cardiac contractility (Kitagawa and Iwaki 1963). The immunostimulatory effects of ginseng were investigated in white shrimp, and the results showed that shrimp fed a ginseng diet had significantly increased antioxidant activity in their gills (Liu et al. 2011).

A reduction in sperm motility may be due to increased latency and decreased frequency of intercourse with aging (Neaves et al. 1984; Hwang et al. 2010). Ginseng helps regulate body functions, specifically improving adaptability, and is believed to enhance sperm production (Francis et al. 2002c). There are many reported mechanisms of action of ginsenosides, metabolites found in ginseng, that suggest individual ginsenosides may exert specific tissue dependent actions (Kim et al. 2000; Murphy and Lee 2002). Murphy and Lee (2002) have focused on the effects of ginseng on sexual behavior and performance in rats and mice. They found that ginseng significantly enhanced libido and copulatory behavior in male rats and mice.

One of the most important factors affecting reproduction in fish is the quality of sperm and eggs. Therefore, it is important to be able to measure the quality of sperm and eggs of broodstocks. Unfortunately, fish experiments with ginseng have been limited. The only previously published study tested the effect of ginseng in Nile tilapia (Ashraf and Goda 2008). This study reported the growth performance, feed utilization, and hematological indices of the fish. Therefore, the main objectives of our study are to assess the effect of ginseng on sperm quality prior to fertilization in rainbow trout, including macroscopic and microscopic examination of sperm, mass movement of sperm, sperm motility, sperm density, ratio of living spermatozoon, fertilization and insemination success, and the ratio of living embryos.

\section{Broodstock Selection and Maintenance}

\section{Materials and Methods}

The broodstocks were selected on the basis of their morphological or external sexual characteristics. Recent matured rainbow trout males between 8-9 months old weighing between 230-250 g were used. In each experimental group, 100 fish were stocked in 25 $\mathrm{m}^{3}$ net cages and weighed individually.

Preparation of Extract and Feed

Ginseng leaves (Araliaceae sp.) were acquired from the local plant market, washed in sterile distilled water, air-dried in shade, and powdered. Powdered extract weighing $250 \mathrm{~g}$ was mixed with $500 \mathrm{~mL}$ of $70 \%$ ethanol (Kavitha and Subramanian 2011). The prepared crude extract was used as a stock solution for the entire experiment. Commercial fish feed, which has $42-46 \%$ crude protein (CP), $14-16 \%$ crude lipid (CL), $2-2.5 \%$ crude cellulose (CC) and 9-10\% moisture, was used. Feed was prepared containing Araliaceae 
sp. extract in concentrations of $1 \mathrm{~g} / \mathrm{kg}$ and $2 \mathrm{~g} / \mathrm{kg}$ for the two experimental groups respectively, and a control group with no Araliaceae sp. extract. The experiment was carried out in triplicate for each diet. The fish were fed for 120 days ad libitum and sperm samples were taken from fish for analysis every 30 days of the study.

\section{Gamete Collection}

Sperm and eggs were taken using dry abdominal massage technique. In each fertilization experiment, sperm samples were stripped from 4 males randomly selected from each group and pooled in equal amounts before use for fertilization of eggs.

Sperm Motility

The motility of sperm in each sample was evaluated shortly following sperm collection. All sperm samples were kept at $4^{\circ} \mathrm{C}$ until use for the motility test. Hank's solution was used to dilute the sperm samples (1:20), $1 \mu \mathrm{L}$ of sperm was put on a glass microscope slide, and $10 \mu \mathrm{L}$ of activation solution $(0.9 \% \mathrm{NaCl})$ was added. Spermatozoa motility was observed under $40 \times$ magnification, and the percentage of motile spermatozoa were determined. Sperm were considered motile if they showed only forward movements, whereas simply vibrating sperm were assessed as immobile.

\section{Sperm Density}

The density of spermatozoa was determined by the hemacytometric method. Sperm was diluted $(1: 1000)$ in Ringer solution, and the mean sperm count was determined from three replicate samples for each fish using a Thoma slide at a magnification of $40 \times$, and sperm density was expressed as $\times 10^{9} / \mathrm{mL}$.

Duration of Motility and Sperm $\mathrm{pH}$

The duration of spermatozoa movement was determined by a sensitive chronometer $(1 / 100 \mathrm{~s})$. The timing was simultaneous with the addition of activation solution into the sample. Sperm $\mathrm{pH}$ was quantified using standard $\mathrm{pH}$ electrodes within 10 minutes of sampling.

\section{Reproductive Performance}

To measure the gonadosomatic index (GSI) at the end of the experimental period, 9 male fish were randomly selected from each group, and their testes were removed and weighed. To assess reproduction, three males were randomly selected from each group, and eggs were placed in the recirculation system that was used for the experimental period. A recirculation system changed $10 \%$ of the water every day, and water temperature was fixed at $13^{\circ} \mathrm{C}$. Reproductive parameters were calculated using the following formulae:

(1) GSI $(\%)=($ Gonad weight / Body weight $) \times 100$

(2) Hatching $(\%)=$ (Number of hatched larvae / Number of eggs laid) $\times 100$

(3) Fertilization $(\%)=($ Number of fertilized eggs / Total number of eggs $) \times 100$

Statistical Analysis

The effect of treatment on different parameters was analyzed by one-way analysis of variance, after checking for normality distribution of data. If significant differences were found, Duncan's multiple range tests were performed to calculate the mean differences. Statistical analysis was performed using SPSS ver. 23. Data are expressed as mean \pm SD.

\section{Results}

In our study, the highest GSI values were observed in treatment group $2(2 \mathrm{~g} / \mathrm{kg})$. Additionally, fertilization and hatching ratios of the experimental groups were higher than the control group (Table 1 ).

Table 1. Reproductive performance of experimental groups

\begin{tabular}{lccc} 
& Control & Group 1 $(1 \mathrm{~g} / \mathrm{kg})$ & Group $2(2 \mathrm{~g} / \mathrm{kg})$ \\
\hline Gonadosomatic Index & $4.48 \pm 0.34^{\mathrm{c}}$ & $5.92 \pm 0.21^{\mathrm{b}}$ & $6.20 \pm 0.24^{\mathrm{a}}$ \\
Fertilization Ratio (\%) & $65 \pm 10^{\mathrm{b}}$ & $84.9 \pm 5^{\mathrm{a}}$ & $90 \pm 6^{\mathrm{a}}$ \\
Hatching Ratio (\%) & $57.8 \pm 11.3^{\mathrm{b}}$ & $78.9 \pm 8.06^{\mathrm{a}}$ & $85.2 \pm 7.01^{\mathrm{a}}$ \\
\hline
\end{tabular}

Data are reported as mean \pm SD of three and nine replicates $(n=3, n=9)$. Means with different superscript letter in a row are significantly different $(P<0.05)$. 
In our experiments, higher sperm density was observed in group 2 . The $\mathrm{pH}$ values of all experimental groups were not significantly different $(P<0.05)$. Measurements of the average and highest sperm motility of each experimental group and the motility time were observed (Table 2).

Table 2. Spermatological properties

\begin{tabular}{lccc}
\hline & Control & Group 1 & Group 2 \\
\hline Sperm Motility & $75.7 \pm 5.3^{\mathrm{b}}$ & $90.2 \pm 5.1^{\mathrm{a}}$ & $95.0 \pm 5.0^{\mathrm{a}}$ \\
Motility Time $(\mathrm{sec})$ & $47.0 \pm 4.0^{\mathrm{b}}$ & $57.0 \pm 5.0^{\mathrm{a}}$ & $59.0 \pm 6.0^{\mathrm{a}}$ \\
Sperm Density $\left(\times 10^{9}\right)$ & $7.74 \pm 0.61^{\mathrm{b}}$ & $8.62 \pm 0.53^{\mathrm{b}}$ & $11.27 \pm 0.78^{\mathrm{a}}$ \\
Sperm pH & $7.2 \pm 0.4$ & $7.3 \pm 0.2$ & $7.1 \pm 0.3$
\end{tabular}

Data are reported as mean \pm SD of nine replicates $(n=9)$. Means with different superscript letter in a row are significantly different $(P<0.05)$.

\section{Discussion}

The present study investigated sperm quality parameters and reproductive performance of male rainbow trout given ginseng supplementation in their feed. Previous studies showed the effects of ginseng extract on growth performance, feed utilization, and hematological indices of fish (Ashraf and Goda 2008; Reverter et al. 2014). However, the effects of ginseng on reproductive performance of male fish were not tested.

Some nutrients in feeds increase the fertilization rate in fish. It has been determined that the essential fatty acid content of the broodstock feed of rainbow trout and European sea bass species has a positive effect on sperm quality (Watanabe et al., 1984; Labbe et al., 1993). In our study, commercial broodstock feed was used in all experimental groups but ginseng root extract was added only in groups 1 and 2 and fed 3 months before the reproduction period. Results showed that ginseng extract caused sperm quality to improve.

Sperm density, motility, and duration of motility, have been used for determination of sperm quality (Billard and Cosson, 1992). Poor motility leads to low male fertility (Lahnsteiner et al., 1998) therefore a strong relationship exists between sperm motility and the reproductive performance of fish. Based on this, it can be concluded that increase in motility leads to increased reproduction. Reproductive capacity is the most conclusive way of testing sperm motility (Olaniyi et al. 2016). Supplementation of Ergosan, an algine based complimentary feedstuff for fish and crustaceans significantly increased the spermatocrit value and sperm count (Sheikhzadeh et al., 2010). Similarly, an increase in sperm count and spermatocrit was observed in rainbow trout fed with 800 $\mathrm{mg} / \mathrm{kg}$ ascorbic acid (Canyurt and Akhan, 2008). Fertilization (\%) decreased significantly in $2 \mathrm{~g} / \mathrm{kg} T$. terrestris extract $(83.12 \pm 1.45)$ when compared with the control and the other groups (Yeganeh et al., 2017).

The results show that higher levels of ginseng in feed, enhanced sperm motility in the experimental groups compared to the control. In addition, the fertilization ratio of the experimental groups was higher than the control.

This study indicated that sperm quality is affected by addition of ginseng extract into rainbow trout feed. Our data can be used to obtain high quality males for the fertilization of trout eggs by supplementing ginseng in their diets. Use of organic materials such as medicinal plants in fish can be efficient in achieving sustainable, economical, and safe trout production in commercial aquaculture.

\section{Acknowledgements}

This study was supported by Kastamonu University Coordinatorship of Scientific Research Projects (KÜ-BAP05/2015-11).

\section{References}

Adedeji, O.S., Farimi, G.O., Ameen, S.A. and Olayemi, J.B., 2006. Effects of bitter kola (Garcinia kola) as growth promoter in Broiler Chicks from day old to four weeks old. J. Anim. Vet. Adv. 5, 191-193.

Adeparusi, E.O., Dada, A.A., Alale, O.V., 2010. Effects of medicinal plant (Kigelia africana) on sperm quality of African catfish Clarias gariepinus (Burchel, 1822) Broodstock. J. Agric. Sci. 2, 193. https://doi.org/10.5539/jas.v2n1p193. 
Ashraf, M.A., Goda S., 2008. Effect of dietary ginseng herb (Ginsang G115) supplementation on growth, feed utilization, and hematological indices of Nile Tilapia, Oreochromis niloticus (L.), Fingerlings. J. World. Aquac. Soc. 39, 205-214.

Attele, A.S., Wu, J.A., Yuan, C.S., 1999. Ginseng pharmacology, multiple constituents and multiple actions. Biochem. Pharmacol. 58, 1685-1693.

Baeg, I.H., So, S.H., 2013. The world ginseng market and the ginseng (Korea). J. Ginseng. Res. 37, 1-7.

Bai D.Q.*, Li R., Xing K.Z., Guo Y.J., Chen C.X., Qiao X.T., Mao H.T. and Zhu G.X., 2009. In vitro Antibacterial Activity of Herbal Medicines and Combinations of Herbal Medicines and Antibiotics against Edwardsiella tarda. Isr. J. Aquacult.-Bamidgeh, AquacultureHub, 61(1), 27-34.

Bhuvaneswari, R., \& Balasundaram, C., 2006. Traditional Indian herbal extracts used in vitro against growth of the pathogenic bacteria-Aeromonas hydrophila. Isr. J. Aquacult.-Bamidgeh, AquacultureHub, 58(2), 89-96.

Bilen, S., Özkan, O., Alagöz, K., Özdemir, K.Y.*, 2018. Effect Of dill (Anethum graveolens) and garden cress (Lepidium sativum) dietary supplementation on growth performance, digestive enzyme activities and immune responses of juvenile common carp (Cyprinus carpio). Aquaculture, 495:611-616.

Billard, R., Cosson, M.P., 1992. Some problems related to the assessment of sperm motility in freshwater fish. J. Exp. Zool. 261, 122-131.

Canyurt, M.A., Akhan, S., 2008. Effect of ascorbic acid supplementation on sperm quality of rainbow trout (Onchorynchus mykiss). Turk. J. Fish. Aqua. Sci. 8, 171-175.

Dada, A.A., 2015. Use of fluted pumpkin (Telfairia occidentalis) leaf powder as feed additive in African catfish (Clarias gariepinus) fingerlings. Int J Biol Chem Sci., 9, 301307. http://dx.doi.org/10.4314/ijbcs.v9i1.27

Dada, A.A., Ajilore, V.O., 2009. Use of ethanol extracts of Garcinia Kola as fertility enhancer in female catfish Clarias gariepinus broodstock. Int J Fish Aquacult., 1, 1-5.

Francis, G., Kerem, Z., Makkar, H.P.S., Becker, K., 2002. The biological action of aponins in animal systems: a review. Br. J. Nutr. 88, 587-605.

Gillis, C.N., 1997. Ginseng pharmacology, a nitric oxide link. Biochem. Pharmacol. 54, $1-8$.

Hwang, S.Y., Sohn, S.H., Wee, J.J., Yang, J.B., Kyung, J.S., Kwak, Y.S., Kim, S.W., Kim, S.K., 2010. Panax ginseng improves senile testicular function in rats. J. Ginseng Res. 34, 327-335.

Kavitha, P., Subramanian, P., 2011. Influence of Tribulus terrestris on testicular enzyme in fresh water ornamental fish Poecilia latipinna. Fish Physiol. Biochem. 37, 801-807. http://dx.doi.org/10.1007/s10695-011-9478-z.

Kim, W.Y., Kim, J.M., Han, S.B., Lee, S.K., Kim, N.D., Park, M.K., Kim, C.K., Park, J.H., 2000. Steaming of ginseng at high temperature enhances biological activity. J. Nat. Prod. 63, 1702-1704.

Kitagawa, H., Iwaki, D., 1963. Pharmacological studies of the drug ginseng. Folio Pharmacologica Japonica 59, 348-354.

Labbe, C., Loir, M., Kaushik, S., Maisse, G., 1993. The influence of both rearing and dietary lipid origin on fatty acid composition of spermatozoan polar lipids in rainbow trout (Oncorrhynchus mykiss). Effect on sperm cryopreservation tolerance. Fish Nutrition in Practice, Biarritz (France), June 24-27, 1991. Ed. INRA, Paris 1993, (Les Colloques, no. 61), pp. 49-59.

Lahnsteiner, F., Berger, B., Weismann, T., Patzner, R.A., 1998. Determination of semen quality of the rainbow trout. Oncorhynchus mykiss, by sperm motility, seminal plasma parameters, and sperm metabolism. Aquaculture 163, 163-181.

Liu, X.L., Xi, Q.Y., Yang, L., Li, H.Y., Jiang, Q.Y., Shu, G., Wang, S.B., Gao, P., Zhu, X.T., Zhang, Y.L., 2011. The effect of dietary Panax ginseng polysaccharide extract on the immune responses in white shrimp, Litopenaeus vannamei. Fish Shellfish Immunol. 30, 495-500.

Murphy, L.L., Lee, T.J.F., 2002. Ginseng, sex behavior, and nitric oxide. Anm. N.Y. Acad. Sci. 962, 372-377. 
Neaves, W.B., Johnson, L., Porter, J.C., Parker, C.R., Jr., Petty, C.S., 1984, Leydig cell numbers, daily sperm production, and serum gonadotropin levels in aging men. J. Clin. Endocrinol. Metab. 59, 756-763.

Olaniyi, C.O., Adebowale, T.T., Mustapha, R.O., 2016. Effect of mulberry leaf meal on growth and reproductive performance of African catfish. J. Zool. 5, 20-24. http://www.cibtech.org/cjz.htm

Reverter, M., Bontemps, N., Lecchini, D., Banaigs, B., Sasal, P., 2014. Use of plant extracts in fish aquaculture as an alternative chemotherapy: Current status and future perspectives. Aquaculture 433, 50-61.

Sheikhzadeh, N., Reza, A., Razi Allah, J. J., \& Hossein, T.-N., 2010. Effect of Ergosan on semen quality of male rainbow trout (Oncorhynchus mykiss) broodstock. Animal Reproduction Science, 122(3-4), 183-188.doi:10.1016/j.anireprosci.2010.08.008

Watanabe, T., Takeuchi, T., Saito, M., Nishimura, K., 1984. Effect of low protein-high calorie or essential fatty acid deficiency diet on reproduction of rainbow trout. Nippon Suisan Gakkaishi, 50 (7), 1207-1215.

Yeganeh, S., Sotoudeh, A., Movaffagh, A.N., 2017. Effects of Tribulus terrestris extract on growth and reproductive performance of male convict cichlid (Cichlasoma nigrofasciatum). Turk. J. Fish. Aquat. Sci. 17, 1003-1007. 